\title{
Meeting information and research needs of health policy students: overcoming the challenges
}

\author{
Thumeka Mgwigwi
}

\begin{abstract}
Health policy is a diverse field that requires knowledge of databases and other sources of information outside the health field. Librarians are faced with a challenge of bringing awareness to these information sources for the benefit of researchers and students in the field. The purpose of this paper is to highlight some of the efforts undertaken by the author to assist students enrolled in the Health Policy and Management program at York University in Toronto, Ontario, Canada in identifying health literature in nonhealth and medical databases. A review of the literature reveals that there is less focus on information needs of health policy students compared with information needs of nursing and (or) medical students.
\end{abstract}

\section{Introduction}

When it comes to finding health-related literature, medical and nursing databases like Medline and Cumulative Index to Nursing and Allied Health Literature (CINAHL) seem to be the first choice for health policy students. As the health policy field is diverse in nature, reliance on mainstream medical databases may not be enough to satisfy a research need. To maximize the effectiveness of health policy research, health policy students need to look beyond the obvious databases and search databases that are associated with other fields, like economics, public policy, law, or business.

This paper will highlight some of the efforts undertaken by the author to assist students enrolled in the Health Policy and Management program at York University in Toronto, Ontario, Canada in identifying health literature in nonmedical databases. Students in the Health Policy and Management program differ from students enrolled in programs like medicine and nursing, as their information needs are nonclinical or nonbiomedical in nature. However, the information needs of doctors, nurse practitioners, and other health care providers are well catered to. Most students enrolled in the Health Policy and Management program do not fall into the aforementioned programs, as they study to become policy makers, work for government agencies, research institutions, international agencies, and pharmaceutical companies, to name a few.

An attempt was made to identify literature that focuses on the information needs of health policy researchers by searching the Library and Information Science Abstracts (LISA) and Library Literature databases. Using the keywords "health policy" and "information needs" retrieved only two citations in LISA and nine citations in Library Literature. The search was revised using the keywords "health information needs", which retrieved 66 citations in LISA and 102 citations in Library Literature. Upon surveying the search results, it became clear that much of the literature focused more on the information needs of consumers, health practitioners, and medical and nursing students. An article by Humphreys states that "there is a dearth of formal studies of information needs and information-seeking behavior in health policy and public health" [1]. Although Humphrey's article does not focus on students, it does bring to the forefront the fact that individuals seeking clinical information are more likely to be well served than those who seek health policy and public health information.

Lasker's article mentions that the problem with serving the health policy and public health community stems from the diverse nature of the field, as the information sought by health policy professionals encompasses "statistical and epidemiological data, legal and legislative documents, information about community resources, and an amorphous, and sometimes ephemeral, "grey literature" [2].

Finding relevant information in traditional healthrelated and biomedical databases like Medline is also a challenge as evidenced in an article by Greyson [3]. To reemphasize the diverse nature of the health policy field, Greyson mentions that some of the material may be found in nonmedical databases related to business or economics.

\section{Brief background of the Health Policy and Management program at York University}

York University's School of Health Policy and Management [4] is part of the university's Faculty of Health. The school offers both undergraduate and graduate programs. Health Studies is the undergraduate program with a focus on general education for the first and second years of study. The third and fourth years of study has four areas: General Honours Bachelor of Health Studies, Health Management, Health Policy, and Health Informatics. Health Management focuses on managing health services organizations, organizational behavior, leadership, financial management, 
and health system performance, while Health Informatics focuses on e-health, electronic health records, and collection and analysis of health information. Lastly, Health Policy is concerned with the politics of the health system, pharmaceutical policy, comparative health policy, public policy, and disability and mental health policy.

Graduate programs are composed of Critical Disability Studies, which leads to a Masters program. The Masters program encompasses various aspects like law, anthropology, health studies, geography, economics, education, labor studies, political science, etc. A Ph.D. program has areas of specialization in human rights, critical theory, and social policy. The graduate program in Health offers a Masters and Ph.D. in Health Policy and Equity focusing on inequality in health and the delivery of health care.

\section{The nature of the challenge}

The challenge with meeting the information needs of health policy students is not a lack of resources but rather the diversity of resources that may not be well organized. Some students in general lack the necessary research skills required to navigate their library's resources, especially if they have not consulted a librarian. The same applies to health policy students who may not be aware of the available literature from nonmedical databases. A student looking for information on health care reform, for instance, may not think to search a public policy database like the Public Affairs Information Service (PAIS), while a nursing student looking for information on palliative care will go directly to a nursing database like CINAHL.

Another challenge may come from faculty who may not think to recommend to their students that they consult a librarian. As students are more likely to read articles suggested by their professor, they are also likely to seek a librarian's assistance if their professor makes that recommendation.

\section{Program description}

At York University Libraries, graduate students have access to subject librarians for one-on-one research consultations to assist them with their research. The need to introduce nonmedical databases to health policy students came to light after these consultation sessions with health policy students. The sessions often began with a brief interview to gather information on how far the students were in their research process. It became clear that there was emphasis and reliance on mainstream medical databases.

The libraries do, however, provide instruction sessions for students that are offered on an on-demand basis when students have an assignment and a faculty member makes a request for instruction. The instruction sessions are often tailored to meet the requirements of the assignment. Other instruction sessions are drop-in workshops, with graduate and undergraduate sessions offered separately. The drop-in workshops are usually offered at the beginning of the fall and winter semesters and the sessions are more general in nature, so the content may not always cater to every student.

To reduce dependence on mainstream medical databases, the author conducted a pilot project at the beginning of 2008 . The project consisted of specialized hands-on research instruction seminars for graduate students enrolled in the Health Policy and Management program. The seminars were advertised through the graduate student's listserv. The following nonmedical databases were used during the seminars: Canadian Periodicals Index Quarterly, Canadian Business and Current Affairs (CBCA), Sociological Abstracts, PAIS, and EconLit.

The specialized seminars were then followed by individual consultations with the students that lasted between 1 and 2 hours depending on the nature of the research project. The purpose of the consultation sessions was to ensure that students' unique research needs were met, as they were working on different research projects. Details about a student's research project were communicated via e-mail at the point of setting up a consultation session. When students did not provide their research project in advance, the consultation would typically begin with an in-depth interview. As the individual consultation sessions were tailored to the student's research needs, the focus was no longer on retrieving health information from nonmedical databases; consequently, other databases like CINAHL, Medline, Web of Science, and Proquest Dissertations and Theses were introduced to students. In some cases, when students were in the early stages of the research process, it was necessary to discuss with them how to negotiate and focus their topic.

\section{Outcomes}

Before the specialized seminars and consultation sessions took place, students showed little knowledge and awareness of the benefit of using nonmedical databases for health research. This was despite the fact that some students had previously attended library instruction sessions as undergraduate students. After each consultation session, a followup e-mail was sent to the students soliciting their opinions about the sessions. Based on this informal feedback, comments from the students were generally positive. However, there were students who made appointments for consultations who were unable to attend the seminars due to time issues or other commitments.

Although topic negotiation was not the primary focus of the sessions, students liked learning about how to focus their research topics and appreciated learning about the benefits of searching Proquest Dissertations and Theses and performing a citation search on Web of Science. Students' realization of the benefit of having access to a librarian was another positive result of the consultation sessions.

\section{Discussion}

Organizing specialized seminars for health policy students yielded positive results; however, there may be other avenues to investigate and utilize. Similar seminars can be offered to faculty as well. There are occasions when faculty indicate that they are not aware of certain library resources, especially when they bring students to the library for an instruction session. Once faculty are aware of these library resources, they are more likely to pass this information along to their students. In some cases where 
health policy students need information related to data, statistics, and government documents, collaboration librarians specializing in these areas might be necessary. Some online learning tools like TechSmith's Camtasia, Adobe Captivate, and Adobe Connect are also being explored for convenience and to make the training sessions available at the point of need. To gain a clearer understanding of the usefulness of the sessions, more formalized surveys will be conducted, as these sessions will continue to be offered.

There is no doubt that information and resources to satisfy health policy research are not lacking. It is our obligation as librarians to recognize, make accessible, and build awareness among health policy students those resources that may not be obvious but that are relevant to the diverse field of health policy.

\section{References}

1. Humphreys BL. Meeting information needs in health policy and public health: priorities for the National Library of Medicine and the National Network of Libraries of Medicine. J Urban Health. 1998;75(4):878-83.

2. Lasker RD. Challenges to accessing useful information in health policy and public health: an introduction to a national forum held at the New York Academy of Medicine, 23 March 1998. J Urban Health. 1998;75(4):779-784.

3. Greyson D. Non-biomedical sources for systematic reviews of pharmaceutical policy. J Med Libr Assoc. 2010 Jan;98(1):8587.

4. York University, Faculty of Health. School of Health Policy and Management. 2010 [cited 20 December 2010]. Available from: http://www.yorku.ca/health/shpm/index.html. 